\title{
Fundamental roles of the innate-like repertoire of natural antibodies in immune homeostasis
}

\author{
Jaya Vas ${ }^{1}$, Caroline Grönwall ${ }^{1}$ and Gregg J. Silverman ${ }^{1,2} *$ \\ 1 Laboratory of B Cell Immunobiology, Department of Medicine, New York University School of Medicine, New York, NY, USA \\ ${ }^{2}$ Laboratory of B Cell Immunobiology, Department of Pathology, New York University School of Medicine, New York, NY, USA
}

\section{Edited by:}

Harry W. Schroeder, University of Alabama at Birmingham, USA

\section{Reviewed by:}

Harry W. Schroeder, University of Alabama at Birmingham, USA

David Nemazee, The Scripps

Research Institute, USA

\section{*Correspondence:}

Gregg J. Silverman, Laboratory of B Cell Immunobiology, Department of Medicine, New York University School of Medicine, Alexandria Center for Life Science, 450 East 29th Street Room 804, New York, NY 10016, USA. e-mail: gregg.silverman@nyumc.org
The composition of the early immune repertoire is biased with prominent expression of spontaneously arising $\mathrm{B}$ cell clones that produce $\operatorname{lgM}$ with recurrent and often autoreactive binding specificities. Amongst these naturally arising antibodies (NAbs) are IgM antibodies that specifically recognized amaged and senescent cells, often via oxidation-associated neo-determinants. These NAbs are present from birth and can be further boosted by apoptotic cell challenge. Recent studies have shown that IgM NAb to apoptotic cells can enhance phagocytic clearance, as well as suppress proinflammatory responses induced via Toll-like receptors, and block pathogenic IgG-immune complex (IC)-mediated inflammatory responses. Specific antibody effector functions appear to be involved, as these anti-inflammatory properties are dependent on IgM-mediated recruitment of the early recognition factors of complement. Clinical surveys have suggested that anti-apoptotic cell (AC) IgM NAbs may modulate disease activity in some patients with autoimmune disease. In mechanistic studies, anti-AC NAbs were shown to act in dendritic cells by inhibition of the mitogen-activated protein kinase (MAPK) pathway, a primary signal transduction pathway that controls inflammatory responses. This immunomodulatory pathway has an absolute requirement for the induction of MAPK phosphatase-1. Taken together, recent studies have elucidated the novel properties of a class of protective NAbs, which may directly blunt inflammatory responses through a primitive pathway for regulation of the innate immune system.

\section{Keywords: immunoregulation, innate-like, natural antibody}

\section{INTRODUCTION}

The evolutionary emergence of the combinatorial antigen receptor system of variable region ( V) gene rearrangements in lymphocytes has provided a greatly enhanced capacity for specific recognition of an immense range of ligands. In humans, the antibody system can generate $\mathrm{B}$ cell antigen receptors (BCR) encoded by more than $10^{20}$ genetically distinct variable region rearrangements. Considering that each individual has only about $10^{11}$ lymphocytes, if the primary B cell repertoire was indeed generated randomly, there would belittle or no recurrence in the antibody gene sequences in the somatically generated repertoires of the billions of humans on the planet. In the following sections, we review evidence the B cell compartment arises during development with a restricted and biased repertoire, and that the antibody products of these B cell clones may serve to protect the host from both external threats and for the maintenance of internal homeostasis.

\section{RESTRICTION IN THE EARLY REPERTOIRE}

In the mouse, there is a remarkable restriction in the usage patterns of the heavy chain $\mathrm{V}$ region $\left(\mathrm{V}_{\mathrm{H}}\right)$ genes during early repertoire development (Perlmutter et al., 1985). Surveys of murine antibody sequences have provided extensive evidence of recurrent lymphocyte clones with the same $\mathrm{V}$ gene rearrangements in different individuals (Seidl et al., 1997), and emerging data suggests there may be similar patterns in the human B cell repertoire (Jackson et al., 2012). In fact, these biases in the expression of $V_{H}$ rearrangements are first detectable at a time point at which representation cannot be affected by antigenic selection of these IgM-associated clones (Schroeder et al., 1987; Schroeder and Wang, 1990). Moreover, a recent report suggested that the perinatal $\mathrm{V}_{\mathrm{H}}$ repertoire expressed in human IgA may be even more restricted than the IgM pool (Rogosch et al., 2012). Recurrent biases in the $V_{H}$ expression in the early B cell repertoire have also been reported in other species, such as swine (Sun et al., 1998) and sheep (Jenne et al., 2006), as well as more primitive species, such as the amphibian Xenopus laevis (Flajnik and Rumfelt, 2000), and zebrafish (Du Pasquier et al., 2000).

Both humans and mice have circulating IgM antibodies that arise early life without immunogenic challenge and have therefore been termed natural antibodies (NAbs). In fact, neonatal $\mathrm{B}$ cells produce IgM antibodies that are readily detectable in the bloodstream at birth, and studies in mice have shown that more than $80 \%$ of circulating IgM are produced by a phenotypically distinct mature B cell subset, termed the B-1a cell subset, and characterized by membrane-associated CD5. In general, while some B-1 cells express antigen-receptors for recognition of common bacterial Ags, some B-1 cell clones can also recognize self-antigens, including the phospholipidphosphatidylcholine (PtC), the phospholipid-associated phosphorylcholine (PC) head 
group, as well as DNA and certain cell membrane proteins (Kantor and Herzenberg, 1993).

B-1 cells are believed to represent a developmentally distinct lineage from their adult counterpart, the bone marrow-derived B-2 subset (reviewed in Hardy, 2006; Baumgarth, 2011). Murine B-1 clones are self-replenishing, which ensures the maintenance of this repertoire, as later in life the capacity for de novo generation of mature lymphocytes with the B-1 cell phenotype is limited. Studies by Notkins and colleagues have shown that CD5-bearing human $\mathrm{B}$ cells also have a bias toward the production of certain types of autoantibodies (Casali and Notkins, 1989). However, CD5 molecules can represent an activation marker on human B cells, and hence by itself CD5 may not be a rigorous phenotypic marker for this B cell subset in humans (Cong et al., 1991). To address this long standing issue, Rothstein and coworkers have reported a detailed phenotyping scheme, in addition to CD5, for identifying human B cells with the diagnostic features of B-1 cells. The repertoire of these human B-1 cells also appeared to include prominent expression of self-specificities for native DNA and PC-containing antigens (Griffin et al., 2011).

\section{AUTOREACTIVITY OF B LYMPHOCYTE SUBSETS}

In mice, mature B-1 and B-2 lymphocyte subsets can play discrete but complementary functional roles in host defenses (reviewed in Baumgarth, 2011). There are also subpopulations within B-1 cells in addition to $\mathrm{CD}^{+} \mathrm{B}-1 \mathrm{a}$ cells, as $\mathrm{B}-1 \mathrm{~b}$ cells (that do not express CD5) make essential contributions to $\mathrm{T}$ cell-independent defenses for certain types of infections (Alugupalli and Abraham, 2009). The clonal selection of these distinct B cell subsets may in part reflect differences in their cellular thresholds for negative selection (i.e., BCR-induced cell death) and in their activation requirements for second signals after $\mathrm{BCR}$ stimulation. By one estimate, over $70 \%$ of BCR-expressing immature B cells in the bone marrow display some level of autoreactivity while the level is much less in recirculating naïve mature B-2 cells (Wardemann et al., 2003). Hence, the immune tolerance checkpoints for B-2 cells that arise from precursors in the bone marrow appear to be generally more stringent in the removal of self-reactivity (i.e., negative selection). In contrast, conserved B-1 cell clonotypes may be positively selected (i.e., enhanced survival and clonal proliferation) by certain types of non-protein self-antigens (Hayakawa et al., 1999), which may include specific types of intracellular antigens (Ferry et al., 2007). As B-1 cells are a major source of circulating IgM in neonates, this may explain why neonatal IgM-NAbs from umbilical cord commonly display features of self-reactivity (Chou et al., 2009).

In the human immune system there is a remarkably strong association between the immune recognition of cell surface $\mathrm{N}$-acetyllactosamine/polylactosamine determinants in glycoconjugates and the usage of the $\mathrm{V}_{\mathrm{H}} 4-34$ gene segment (originally termed $\mathrm{V}_{\mathrm{H}} 4-21$; Silberstein et al., 1991). N-acetyllactosamine/polylactosamine moieties are common on cell surfaces throughout the body, as these are structural components of the I/i blood group antigens and also constitute the antigenic target of pathogenic autoantibodies in cold-agglutinin disease (Silverman et al., 1990; Silberstein et al., 1991; Grillot-Courvalin et al., 1992; Pascual and Capra, 1992).
The immune recognition of I/i related non-protein antigens may be involved in very different types of immune responses. Using a lectin microarray system, exosomes released by human tumor cell lines were shown to express a shared polylactosamine glycan signature (Batista et al., 2011). These findings extend earlier evidence that $\mathrm{I} / \mathrm{i}$ related determinants can be preferentially expressed on cells during early development and on their malignant counterparts (i.e., onco-fetal antigens; Feizi, 1988). In addition, $\mathrm{V}_{\mathrm{H}} 4$-34 encoded autoantibodies were found to commonly bind to HIV-1 envelope determinants (Kobie et al., 2012). Batista et al. (2011) have suggested that these glycans reflect a recurrent type of glycan epitope profile on stressed and apoptotic cells (ACs). Taken together, these findings highlight the intertwined nature of immunodominant determinants on microparticles, exosomes, and HIV-1 virions that arise by budding through the membranes of stressed host cells.

$\mathrm{B}$ cell receptor encoded by $\mathrm{V}_{\mathrm{H}}$ 4-34 rearrangements recognize $\mathrm{I} / \mathrm{i}$ determinants via contact sites associated with a $\mathrm{V}_{\mathrm{H}}$ germline framework subdomain sequences - there is little apparent contribution from the somatically generated heavy chain CDR3 or by the paired light chain (Pascual et al., 1991). Using the 9G4 antiidiotype antibody, $\mathrm{B}$ cells that bear non-mutated $\mathrm{V}_{\mathrm{H}} 4-34$ products have been shown to be highly represented, and whereas in healthy individuals these autoreactive germline B cells were shown to be excluded from T cell-dependent germinal center reactions (PughBernard et al., 2001), these $\mathrm{V}_{\mathrm{H}}$ defined clones can be actively recruited into the germinal center reactions in patients with systemic lupus erythematosus (SLE; Cappione et al., 2005). These findings have been interpreted as evidence of immune defects in SLE patients related to the regulation of autoreactive B cells, although this topic remains controversial.

\section{NATURAL ANTIBODIES AND IMMUNE RECOGNITION OF DAMAGED AND APOPTOTIC CELLS}

During the process of AC death, different cell membraneassociated phospholipids can undergo selective enzyme-mediated and oxidation associated modifications, and these cell membrane neo-determinants become available for recognition by the immune system. Among these, phosphatidylserine (PS) becomes oxidized and rapidly translocates from the inner to the outer leaflet of the cell membrane upon the initiation of apoptosis, where it can serve as a recognition signal for ingestion by professional phagocytes (i.e., "eat me" signal). Apoptosis can also be associated with other lipid neo-determinants, such as malondialdehyde (MDA), which is formed from interactions of unsaturated lipids with reactive oxidation species. Oxidative modifications of the abundantly distributed neutral phospholipid, PtC, also affect the distribution and/or conformation of the PC head group (Friedman et al., 2002), which renders it accessible for antibody recognition. These PC-antigens, as well as MDA-containing antigens, are immunodominant within murine $\mathrm{B}$ cell clonal responses that are boosted by intravenous infusions of ACs (Chen et al., 2009b).

The dominant natural antibody-producing anti-PC B cell clone, termed T15 (also TEPC15), has recurrently been isolated in anti-PC responses. The high representation of this clone in the early repertoire in part reflects a bias for increased representation of the specific $\mathrm{V}_{\mathrm{H}} \mathrm{S} 107.1$ gene rearrangements used by the 
T15 clone (Feeney, 1991). In fact both of the $V_{H}$ and $V_{L}$ rearrangements in the $\mathrm{T} 15$ clone are formed by primary sequence direct rearrangements, and are without somatic mutations. The invariance of the T15 clonotypic NAb therefore is reminiscent of germline encoded receptors of the innate immune system (discussed in Shaw et al., 2000). In fact, T15 clonotypic antibodies are highly specific for PC determinants (Kearney et al., 1981) and in microarray analysis demonstrated little or no cross-reactivity to a large number of structurally distinct antigens (Chen et al., 2009b). Throughout life, T15-related B-1 cells are a major source of NAbs to a range of PC-containing antigens (Masmoudi et al., 1990), including those present on AC membranes, oxidized low-density lipoprotein (LDL), as well as in pneumococcal bacterial cell wall polysaccharide (Shaw et al., 2003; Chou et al., 2009). Many other B-1 cell clones have been demonstrated to be polyreactive and relatively low-affinity (Kantor and Herzenberg, 1993). However, crystallographic analysis of a $\mathrm{V}_{\mathrm{H}} \mathrm{S} 107.1$ encoded (i.e., T15-related) Fab revealed a deep antigen-binding cleft with substantial binding affinity for the small PC moiety (reviewed in Davies et al., 1975). As a consequence of the dependence of the in vivo anti-PC response on T15 clonotypic B cells, otherwise immunocompetent mice which were made deficient only for the $S 107.1 \mathrm{~V}_{\mathrm{H}}$ gene segment, have highly impaired responses to immune challenge with PC determinants on either ACs or bacteria, and also display impaired immune defenses for S. pneumoniae infection (Mi et al., 2000; Chen et al., 2009b). Taken together, these studies suggest that the antigen binding sites of T15-related antibodies have innate-like properties for recognition of PC-containing antigens are highly represented in the pre-immune repertoire (Kearney, 2005), in part because of their preferentially formation by biases in the somatic diversification mechanisms (Feeney, 1992).

Within the NAb pool there are also other antibodies that recognize distinct sets of neo-determinants that arise following cellular injury. There are at least two self-antigen specificities that have been reported to be associated with post-ischemic injury of endothelial cells (Zhang et al., 2008; Kulik et al., 2009). In addition, there are IgM-NAbs that specifically recognize erythrocytes with cell membrane-associated changes due to senescence or from damage by experimental treatment with the protease, bromalein (Cox and Hardy, 1985; Mercolino et al., 1986; Hardy and Hayakawa, 2005). These antibodies are reported to recognize a determinant involving $\mathrm{PtC}$, although it is unclear whether the accessibility of this PtC-associated red cell epitope results from oxidative modification, or due to loss of erythrocyte membrane proteins. Red cell membrane intrinsic proteins have also been implicated as antigenic targets for IgG-NAbs (Lutz, 2012). Notably, as red cells have neither mitochondria nor nuclei, these cells do not undergo the same apoptosis-associated metabolic changes seen in conventional mitochondria-containing cells. This may explain why PC-related antigens are not prominently displayed on erythrocytes as a consequence of aging. Taken together, the cumulative data suggest that the IgM repertoire may include a range of distinct subsets of autoreactive NAbs, which recognize different cell types affected by apoptosis, injury and senescence, and these NAbs may help to regulate the clearance of different cell types and tissue remodeling as well as modulate innate immune responses.

\section{EFFECTS OF PC-SPECIFIC NATURAL IgIM ON TOLL-LIKE RECEPTOR-INDUCED INFLAMMATION}

Earlier studies have shown that C1q can directly binding to AC membranes and then serve as an "eat-me" signal for the phagocytic clearance of these dying cells (Korb and Ahearn, 1997; Navratil et al., 2001; Ogden et al., 2001). In explanation, C1q may directly interact with externalized PS on these damaged cells (Paidassi et al., 2008). In some settings, the deposition of C1q onto ACs can subsequently have an immunomodulatory effect and inhibit the secretion of proinflammatory cytokines, although by itself these effects are limited (Fraser et al., 2009). Similar properties have also been associated with the mannose-binding lectin (MBL), which triggers the lectin pathway of complement activation. MBL is structurally related to $\mathrm{Clq}$ and these two recognition molecules share a common ancestral genetic origin (Matsushita et al., 2004). Furthermore, MBL can also bind directly to ACs. This may suggest that initiation of apoptosis is associated with a change in the distribution of high-mannose glycoconjugates on the cell membrane (Stuart et al., 2005). These findings are consistent with reports that phagocytes of C1q-deficient mice, as well as MBL-deficient mice, display defects in AC clearance (Quartier et al., 2005; Stuart et al., 2005).

The potential roles of T15 IgM-NAb have been investigated in the innate immune responses of professional phagocytes. As mentioned above, while this IgM natural antibody does not bind healthy cells it can specifically recognize exposed PC determinants on ACs and form complexes (Chen et al., 2009a,b). In turn, these AC-IgM complexes have greatly enhanced capacity to recruit the early complement factors, $\mathrm{Clq}$ and the structurally related $\mathrm{MBL}$, at levels several-fold higher than in the absence of bound IgM. Notably the recruitment of C1q or MBL by IgM-NAb complexes greatly amplifies the capacity for AC phagocytic clearance (Chen et al., 2009a,b; illustrated in Figure 1). These properties are explained by reports that some polymeric IgM, when bound to their cognate antigen, are highly efficient at recruitment of C1q, while other studies have shown that polymeric IgM themselves can contain high mannose glycoconjugates (Arnold et al., 2006). Hence, AC-reactive polymeric IgM may serve to integrate these complement associated innate immune functions (Quartier et al., 2005; Chen et al., 2009a,b).

The formation of IgM-NAb complexes with ACs can also result in strong suppression of in vivo and in vitro inflammatory responses, including those induced by ligands for both membrane-associated and endosomal Toll-like receptors (TLRs), which include TLR3, TLR4, TLR7, and TLR9 (Chen et al., 2009b). These activities are also dependent on the recruitment of C1q and $\mathrm{MBL}$, which are postulated to serve as bridging molecules that trigger phagocyte functions in a way that does not require activation of the complement cascade (Chen et al., 2009a,b). Hence, both the enhancement of apoptotic clearance and the down-modulation of inflammatory responses are therefore pathways by which some NAbs may augment and amplify housekeeping functions that serve to protect the host.

\section{EFFECTS OF THE APOPTOTIC CELL-SPECIFIC NAb-IgIM ON IMMUNE COMPLEX DRIVEN PATHOGENESIS}

During autoimmune pathogenesis high-affinity IgG autoantibodies can make direct contributions by multiple mechanisms 


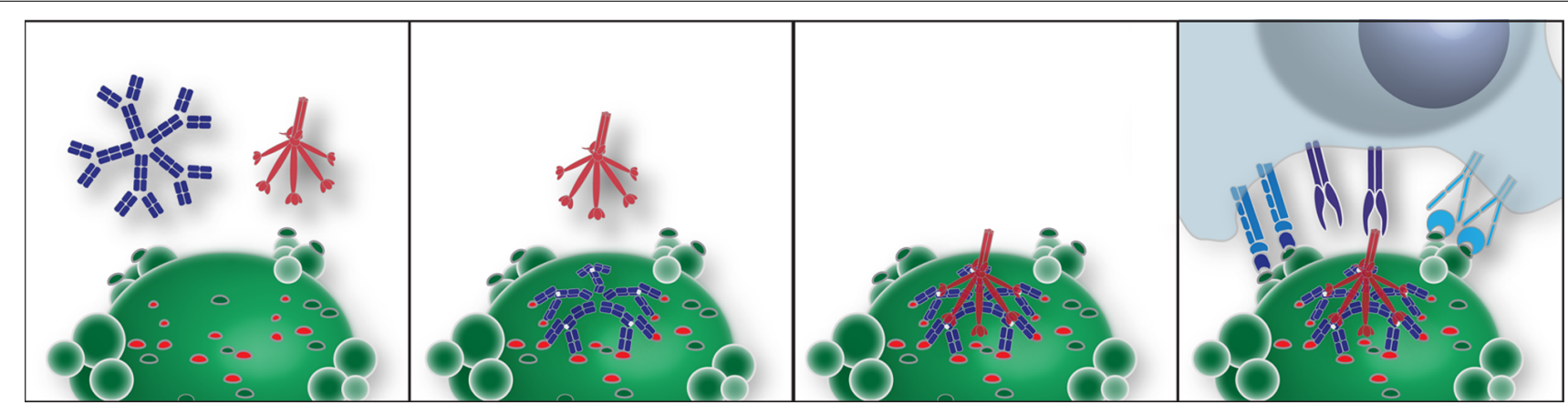

FIGURE 1 | Model of an IgM-NAb complex that enhances interactions between an apoptotic cell and professional phagocytes. In this idealized model, apoptotic death results in membrane alterations that expose a range of neo-determinants. PC-associated membrane determinants are recognized by antigen-binding sites of a pentameric lgM. Binding of PC determinants results in conformational changes in the mu constant regions, which expose a conformational site responsible for recruitment of the globular heads of $\mathrm{C} 1 \mathrm{q}$ (Czajkowsky and Shao, 2009). Alternatively, MBL binds to nearby high mannose N-linked glycoconjugates on mu-associated sites (not shown). This polymeric IgM-C1 q complex is involved in generating or stabilizing interactions with receptors on professional phagocytes, which enhance apoptotic phagocytosis and blocks inflammatory responses. (reviewed in Elkon and Casali, 2008; Lleo et al., 2010). Central to these pathways, many IgG autoantibodies implicated in systemic autoimmune diseases form immune complexes (ICs) with their target antigen, which alter their potential interactions with the host immune system. In sera of patients with conditions such as SLE and Sjogren's syndrome, nucleic acid-recognizing autoantibodies can form ICs with their antigens, ribonucleoproteins, or deoxyribonucleoproteins. These ICs can deposit in tissues such as the kidney, skin, and joints and drive local inflammation and tissue injury by triggering complement cascades (reviewed in Bagavant and Fu, 2009). IgG-ICs might additionally serve as a delivery system to transport self-antigens to endosomal pattern-recognition receptors (PRRs) via uptake by activating Fc receptors. Studies by Marshak-Rothstein, Rifkin, and Rönnblom have demonstrated that DNA or RNA-containing ICs consisting of IgG autoantibodies bound to nuclear debris from dying cells can activate mouse B cells (Leadbetter et al., 2002), conventional dendritic cells (DCs; Boulé etal., 2004), and plasmacytoid DCs (Yasuda et al., 2007) as well as human peripheral blood mononuclear cells (Lövgren et al., 2004). These IgG-nucleic acid ICs can interact with rheumatoid factor autoantibody-bearing B cells (Leadbetter et al., 2002) or with DCs bearing activating $\mathrm{F} c \gamma \mathrm{R}$, which enables the delivery to otherwise inaccessible intracellular compartments. The outcome of this targeted DNA/RNA internalization is the activation of PRRs of the innate immune system, such as the nucleic acid-recognizing TLRs; TLR7 (activated by ssRNA) and TLR8 and TLR9 (activated by DNA). IgG antibodies to the citrullinated self-protein, fibrinogen, which are prevalent in rheumatoid arthritis patients, have also been shown in vitro to activate macrophages through a costimulatory pathway involving both Fc $\gamma \mathrm{R}$ and TLR4 (Sokolove et al., 2011).

The pathogenic influence of IgG autoantibody-ICs can be opposed by IgM natural antibodies to ACs. In vivo studies have shown that administration of anti-PC natural IgM greatly attenuated disease severity in a murine model of collagen-induced arthritis (CIA; Chen et al., 2009a). In this model, immunization with xenogenic collagen II emulsified in complete Freund's adjuvant induces a pathogenic autoimmune response to type II collagen (Terato et al., 1992; Nandakumar et al., 2003), with tissue injury in part mediated through the activating Fc- $\gamma$ receptors (Kleinau et al., 2000). Infusions of IgM-NAbs to ACs also blocked the disease process induced by passive transfer of anti-type II collagen autoantibodies (Chen et al., 2009a), in which inflammatory arthritis is mediated by $\mathrm{Fc} \gamma \mathrm{R}$ and innate immune cells, while lymphocytes do not play central roles (Terato et al., 1992; Nandakumar et al., 2003).

In vitro studies have shown that anti-AC IgM antibodies can directly block the activating effects of lupus-associated IgG autoantibodies on bone marrow-derived DCs (Vas et al., 2012). In fact, the inflammatory effects of both anti-DNA and -RNA IgG-nucleic acid ICs in myeloid DCs were inhibited with suppression of the secretion of inflammatory cytokines IL- 6 and TNF- $\alpha$ (Vas et al., 2012). This IgM-NAb also suppressed IC-mediated induction of cell surface expression of CD80 and CD86, as well as CD40 and other co-stimulatory molecules.

\section{NATURAL ANTIBODY REGULATORY PATHWAYS THAT MODULATE INFLAMMATORY AND AUTOIMMUNE DISEASES}

Serologic surveys of a large cohort of well-characterized SLE patients have further evaluated the potential clinical relevance of IgM autoantibodies to defined oxidation-associated antigenicspecificities, including the apoptosis-associated neo-antigens, PC and MDA. In the lupus cohort, levels of both of these types of IgM autoantibodies were significantly higher compared to healthy adult controls (Grönwall et al., 2012a). Importantly, higher levels of IgM anti-PC correlated with less long-term organ damage, as defined by the SLICC/ACR damage index score, as well as lower disease activity as assessed by the SELENA revision of the SLE disease activity index (SLEDAI) at the time of visit. IgM antiPC levels also correlated with an absence of cardiovascular events, while there were no associations with renal disease (Grönwall et al., 2012a). These results are consistent with a previous report from a smaller cohort of Swedish patients (Su et al., 2008) and with studies showing that lower IgM anti-PC levels are associated with more frequent cardiovascular events in non-autoimmune patients (de Faire et al., 2010; Fiskesund et al., 2010). These findings were in fact 
predicted by earlier studies in atherosclerosis-prone mice (Shaw et al., 2000). Indeed, pneumococcal vaccination, which induces PC-specific antibody responses, was shown to arrest plaque progression in LDL receptor-deficient mice with cholesterol levels over $1000 \mathrm{mg} / \mathrm{dl}$ (Binder et al., 2003). These findings have therefore further strengthened the hypothesis that some anti-AC IgM-NAbs can play protective roles in inflammatory disease.

Yet not every IgM-NAb that recognizes ACs may have equivalent clinical implications. In fact, levels of antibodies to PC and to MDA showed significant differences in their associations with lupus clinical manifestations. IgM anti-MDA showed only weak inverse correlations with the SLICC/ACR damage index but not the SELENA-SLEDAI score and there were also no significant associations with renal disease or cardiovascular events (Grönwall et al., 2012a). These studies also showed that higher levels of the IgM antibody to $\beta 2$-GPI correlated with less organ damage by SLICC/ACR damage index. Furthermore, patients without renal disease had higher levels of IgM anti-CL, and IgM anti-dsDNA (Grönwall et al., 2012a). This may indicate that higher levels of some IgM antibodies may protect some patients from kidney disease, as suggested in an earlier and more focused report (Mehrani and Petri, 2011). Taken together, these studies refute the notion that circulating IgM autoantibodies are inherently polyreactive. Instead, these data strongly argue that the antigenic fine binding specificity of the $\operatorname{IgM}$ determines whether there is an association with protection from certain lupus disease features (Grönwall et al., 2012a). In a recent clinical study, Ajeganova et al. (2011) examined RA patients treated with TNF- $\alpha$ blockers. They observed that levels of PC-specific natural IgM levels were increased in patients treated with TNF- $\alpha$ blockade, while lower anti-PC IgM levels correlated with inferior response to therapeutic intervention for RA disease. Further investigations will be needed to better understand how anti-AC NAbs may modulate the pathogenesis of different autoimmune rheumatic diseases.

\section{MAPK PHOSPHATASE-1 IS REQUIRED FOR NATURAL ANTIBODY SUPPRESSION OF TLR RESPONSES}

Investigations of signal transduction pathways have shown that IgM-NAbs to ACs can affect responses induced by agonists for a broad range of TLRs, by inhibition of the mitogen-activated protein kinase (MAPK) signal transduction system, which plays central roles in the induction and resolution of inflammatory responses (Grönwall et al., 2012b). Inflammatory responses can result from the induction of phosphorylation of one or more of the primary MAPKs; ERK1/2, JNK, and particularly p38, which then translocate to the nucleus where it can affect transcriptional regulation. In rheumatoid arthritis, activated (phosphorylated) p38 is increased in the RA synovium. However, despite evidence that small molecule p38 inhibitors have been effective in mouse models of inflammatory arthritis, efficacy in humans has been limited, which has suggested that an alternate approach to MAPK inhibition may provide greater clinical benefits (reviewed in Hammaker and Firestein, 2010).

To assess the potential relevance of this type of immunomodulatory NAb to clinical autoimmune diseases, the activity of the PC-specific IgM-NAb was also tested in a system in which inflammatory responses are induced by lupus IgG autoantibodies (Vas et al., 2012). These studies demonstrated that this natural IgM inhibited p38 phosphorylation induced in DCs by nucleic acidcontaining IgG autoantibody ICs (Vas et al., 2012). Notably, this inhibitory pathway also blocked the nuclear accumulation of the activated primary MAPKs in myeloid DCs (Vas et al., 2012). In vitro studies of murine bone marrow-derived DCs confirmed that this inhibition was entirely dependent on the recruitment of either C1q or MBL (Grönwall et al., 2012b; illustrated in Figure 1).

The magnitude and duration of MAPK signaling is dependent on the balance between the upstream activators of the system and the deactivation of these kinases by specific phosphatases. Based on evidence that this NAb could affect the activation of each of the three primary MAPKs (Grönwall et al., 2012b), studies were therefore performed that assessed the potential involvement of the regulatory MAPK phosphatases (MKPs), also known as dual-specificity phosphatases (DUSPs). These studies highlighted the role of MKP-1, the archetype for the family, which can serve as the counter-regulatory factor for all three of the primary MAPKs (reviewed in Liu et al., 2007). In fact, the anti-AC IgM-mediated blockade of TLR-mediated MAPK signaling had an absolute requirement for the expression of MKP-1 (Grönwall et al., 2012b). In DCs activated by TLR agonists, the addition of the anti-AC IgM, in the presence of C1q or MBL in serumfree media, resulted in induction within minutes of MKP-1 at a transcript and a protein level, and it rapidly became localized within the nucleus (Grönwall et al., 2012b). Using deconvolutional immunofluorescence microscopy, NAb-mediated MKP-1 accumulation correlated with a reciprocal impairment in the phosphorylation and nuclear translocation of the activated primary MAPK protein molecules. To investigate the relative contribution of MKP-1 to NAb-mediated suppression, responses were compared in DCs from wild-type or MKP-1-deficient mice (Grönwall et al., 2012b). Such MKP-1-deficient mice are reported to exhibit overexuberant inflammatory responses, but no other immune developmental abnormalities (Dorfman et al., 1996; Salojin et al., 2006). These studies confirmed the absolute requirement for MKP-1 for IgM-NAb-mediated inhibition of TLR responses from DCs (Grönwall et al., 2012b).

\section{CONCLUDING REMARKS}

One of the most fundamental challenges faced by the immune system is the efficient recognition and clearance of the body's own cells, which because of senescence or injury enter programmed cell death pathways. While cells dying of apoptotic death pathways do not pose an immediate risk to the host, if these cell corpses are not efficiently removed there is the risk of progression to secondary necrosis. This can lead to the loss of integrity of cell membranes with release of cytoplasmic and nuclear components that can serve as ligands for proinflammatory cellular receptors, and the triggering of autoimmune responses. Hence, throughout the lifespan of multicellular organisms, there is an absolute need for the clearance of the immense number of cell corpses that are generated each day, even in health. As a direct consequence, the immune system has developed a redundant layering of superimposed mechanisms. Hence, the control of apoptotic clearance is intertwined with the regulation and resolution of inflammatory responses. 
At birth, humans already have substantial levels of circulating IgM antibodies, which reflect a functional B cell compartment poised and ready to contribute to neonatal host defenses. These IgM antibodies arise in the womb from neonatal B lymphocytes that express clonally distributed BCRs. However, evidence of recurrent clones suggests that this early B cell repertoire may be affected by in vivo clonal selection that may be a response to evolutionary pressure to provide important housekeeping functions related to apoptotic clearance and avoidance of excessive and damaging inflammatory responses.

IgM-mediated protection from autoimmune disease was first demonstrated in mice deficient in the capacity to secrete $\operatorname{IgM}$ antibodies, as these mice were found to develop pathologic autoimmunity with the production of lupus IgG autoantibodies (Boes et al., 2000; Ehrenstein et al., 2000). Furthermore, in mice predisposed to the development of lupus-like disease, a bias toward secretion of monomeric IgM and lower levels of polymeric IgM can result in accelerated development of lupus-like disease (Youd et al., 2004). It may therefore be relevant that $8 \%$ of a cohort of 300 SLE patients were recently reported to have selective deficiency in serum IgM (Perrazio et al., 2012).

Our studies demonstrated that anti-AC IgM-NAbs, present from early in life, can suppress inflammatory responses mediated by phagocytic cells by induction of MKP-1, which in other settings have been shown to have potent regulatory roles for the MAPK system. MKP-1 is well known for its many counter-regulatory roles, which include the late negative feedback of responses to LPS stimulation, the blunting of responses after rapid re-exposure to a TLR agonist such as LPS tolerance, as well as contributing to the anti-inflammatory properties of glucocorticoids (reviewed in Liu et al., 2007). These studies also documented an additive effect of anti-AC IgM-NAb and dexamethasone for early MKP-1 induction and inhibition of LPS-induced p38 MAPK activation that, when combined, exceeded the maximum effects of either agent alone (Grönwall et al., 2012b). In part, this is likely explained by the additive integration of separate signals received via distinct cell membrane-associated receptors triggered by dexamethasone (i.e., glucocorticoid receptor) or by anti-AC IgM complexes (discussed below). As glucocorticoids are amongst the most widely prescribed treatments for inflammatory and autoimmune diseases, it is indeed intriguing that there is an overlap in the inhibitory signal transduction pathways of glucocorticoids and by the formation of regulatory ICs with early complement recognition factors that are coordinated in their organization by IgM autoantibodies to oxidation-associated neo-determinants on ACs.

\section{REFERENCES}

Ajeganova, S., Fiskesund, R., de Faire, U., Hafström, I., and Frostegård, J. (2011). Effect of biological therapy on levels of atheroprotective antibodies against phosphorylcholine and apolipoproteins in rheumatoid arthritis - a one year study. Clin. Exp. Rheumatol. 29, 942-950.

Alugupalli, K. R., and Abraham, D. (2009). B cell multitasking is required to control nematode infection. Immunity 230, 317-319.

Arnold, J. N., Dwek, R. A., Rudd, P. M., and Sim, R. B. (2006). Mannan binding lectin and its interaction with immunoglobulins in health and in disease. Immunol. Lett. 106, 103-110.

Asai, T, Tena, G., Plotnikova, J., Willmann, M. R., Chiu, W. L., Gomez-Gomez, L., etal. (2002). MAP kinase signalling cascade in Arabidopsis innate immunity. Nature 415, 977-983.

Fundamental to the inhibitory effects of regulatory NAbs, polymeric IgMs that bind ACs can express constant regions with multiple sites for recruitment of $\mathrm{Clq}$, and the $\mathrm{Fc} \mu$ of some IgMNAbs also have high mannose glycoconjugates on that bind MBL (Chen etal., 2009a,b). The potential properties of such complexes suggested by studies with targeted deficiencies in C1q, MBL, or secreted IgM, which each have impaired control of inflammatory responses, and in some cases are predisposed to the development of autoimmune disease (Botto et al., 1998; Boes et al., 2000; Ehrenstein et al., 2000; Stuart et al., 2005). Furthermore, we have previously shown that the complement-dependent immunomodulatory properties of anti-AC IgM, while the recruitment of C1q or MBL was essential, there was no absolute requirement for downstream activation of the complement cascade (Chen et al., 2009a).

These IgM-NAbs to AC-associated determinants can regulate responses mediated by diverse TLRs, an ancient type of innate immune receptor that was first characterized in insects (Lemaitre et al., 1996). Furthermore, mechanistic investigations have shown these effects are linked to modulation of the MAPK signaling system, which is one of the earliest evolutionarily conserved pathways of immunity, being present in plants and mammals (Asai et al., 2002). Likewise, MKP-1 orthologs have also been described in protozoans (Moncho-Amor et al., 2011), and as mentioned above, mice with MKP-1 deficiency have severe defects in the control of innate responses (Salojin et al., 2006). These regulatory properties are expressed by a class of naturally occurring autoreactive antibodies that are postulated to come from the most primitive tier of B cells in the adaptive immune system (Kantor and Herzenberg, 1993).

As ACs are ubiquitous, we wonder whether the high frequency of these innate-like NAb-producing clones in the "preimmune" repertoire in part reflects positive selection of the B-1 cell clones that are reactive with membrane-associated neo-determinants on cells wasted during development. The protective properties of anti-AC NAbs may be mediated by a previously unknown regulatory signaling pathway, which integrates and coordinates the influence of select innate immune factors on myeloid cell function.

\section{ACKNOWLEDGMENTS}

Work in our lab was supported by grants from the NIH; R01AI090118, R01 AI068063 and ARRA supplement, R01AI090118, and from the ACR REF Within Our Reach campaign, the Alliance for Lupus Research, the Arthritis Foundation, and the P. Robert Majumder Charitable Trust.

Bagavant, H., and Fu, S. M. (2009). Pathogenesis of kidney disease in systemic lupus erythematosus. Curr. Opin. Rheumatol. 21, 489-494.

Batista, B. S., Eng, W. S., Pilobello, K. T., Hendricks-Muñoz, K. D., and Mahal, L. K. (2011). Identification of a conserved glycan signature for microvesicles. J. Proteome Res. 10, 4624-4633.

Baumgarth, N. (2011). The double life of a B-1 cell: self-reactivity selects for protective effector functions. Nat. Rev. Immunol. 11, 34-46.

Binder, C. J., Horkko, S., Dewan, A., Chang, M.-K., Kieu, E. P., Goodyear, C. S., et al. (2003). Pneumococcal vaccination decreases atherosclerotic lesion formation: molecular mimicry between Streptococcus pneumoniae and oxidized LDL. Nat. Med. 9, 736-743.

Boes, M., Schmidt, T., Linkemann, K., Beaudette, B. C., Marshak-Rothstein, 
A., and Chen, J. (2000). Accelerated development of IgG autoantibodies and autoimmune disease in the absence of secreted IgM. Proc. Natl. Acad. Sci. U.S.A. 97, 11841189.

Botto, M., Dell'Agnola, C., Bygrave, A. E., Thompson, E. M., Cook, H. T., Petry, F., et al. (1998). Homozygous $\mathrm{Clq}$ deficiency causes glomerulonephritis associated with multiple apoptotic bodies. Nat. Genet. 19, 56-59.

Boulé, M. W., Broughton, C., Mackay, F., Akira, S., Marshak-Rothstein, A., and Rifkin, I. R. (2004). Toll-like receptor 9-dependent and -independent dendritic cell activation by chromatinimmunoglobulin G complexes. J. Exp. Med. 199, 1631-1640.

Cappione, A. III, Anolik, J. H., PughBernard, A., Barnard, J., Dutcher, P., Silverman, G, J., et al. (2005). Germinal center exclusion of autoreactive $B$ cells is defective in human systemic lupus erythematosus. J. Clin. Invest. 115, 3205-3216.

Casali, P., and Notkins, A. L. (1989). Probing the human B-cell prertoire with EBV: polyreactive antibodies and $\mathrm{CD}^{+}{ }^{+}$lymphocytes. Annu. Rev. Immunol. 7, 513-535.

Chen, Y., Khanna, S., Goodyear, C. S., Park, Y. B., Raz, E., Thiel, S., et al. (2009a). Regulation of dendritic cells and macrophages by an anti-apoptotic cell natural antibody that suppresses TLR responses and inhibits inflammatory arthritis. $J$. Immunol. 183, 1346-1359.

Chen, Y., Park, Y. B., Patel, E., and Silverman, G. J. (2009b). IgM antibodies to apoptosis-associated determinants recruit $\mathrm{Clq}$ and enhance dendritic cell phagocytosis of apoptotic cells. $J$. Immunol. 182, 6031-6043.

Chou, M. Y., Fogelstrand, L., Hartvigsen, K., Hansen, L. F., Woelkers, D., Shaw, P. X., et al. (2009). Oxidation-specific epitopes are dominant targets of innate natural antibodies in mice and humans. J. Clin. Invest. 119, 1335-1349.

Cong, Y. Z., Rabin, E., and Wortis, H. H. (1991). Treatment of murine $\mathrm{CD}^{-} \mathrm{B}$ cells with anti-Ig, but not LPS, induces surface CD5: two activation pathways. Int. Immunol. 3, 467-476.

Cox, K. O., and Hardy, S. J. (1985). Autoantibodies against mouse bromelain-modified RBC are specifically inhibited by a common membrane phospholipid, phosphatidylcholine. Immunology 55, 263-269.

Czajkowsky, D. M., and Shao, Z. (2009). The human IgM pentamer is a mushroom-shaped molecule with a flexural bias. Proc. Natl. Acad. Sci. U.S.A. 106, 14960-14965.

Davies, D. R., Padlan, E. A., and Segal, D. M. (1975). Three-dimensional structure of immunoglobulins. Annu. Rev. Biochem. 44, 639-667.

de Faire, U., Su, J., Hua, X., Frostegård, A., Halldin, M., Hellenius, M.-L. et al. (2010). Low levels of IgM antibodies to phosphorylcholine predict cardiovascular disease in 60-year old men: effects on uptake of oxidized LDL in macrophages as a potential mechanism. J. Autoimmun. 34, 73-79.

Dorfman, K., Carrasco, D., Gruda, M., Ryan, C., Lira, S. A., and Bravo, R. (1996). Disruption of the erp/mkp-1 gene does not affect mouse development: normal MAP kinase activity in ERP/MKP-1-deficient fibroblasts. Oncogene 13, 925-931.

Du Pasquier, L., Robert, J., Courtet, M., and Mußmann, R. (2000). Bcell development in the amphibian Xenopus. Immunol. Rev. 175, 201-213.

Ehrenstein, M. R., Cook, H. T., and Neuberger, M. S. (2000) Deficiency in serum immunoglobulin (Ig)M predisposes to development of IgG autoantibodies. J. Exp. Med. 19, 1253-1258.

Elkon, K., and Casali, P. (2008). Nature and functions of autoantibodies. Nat. Clin. Pract. Rheumatol. 4, 491-498.

Feeney, A. J. (1991). Predominance of the T15 anti-phosphorylcholine junctional sequence in neonatal preB cell. J. Immunol. 147, 43434350.

Feeney, A. J. (1992). Predominance of VH-D-JH junctions occurring at sites of short sequence homology results in limited junctional diversity in neonatal antibodies. J. Immunol. 149, 222-229.

Feizi, T. (1988). Carbohydrate structures as onco-developmental antigens and components of receptor systems. Adv. Exp. Med. Biol. 228, 317-329.

Ferry, H., Potter, P. K., Crockford, T. L., Nijnik, A., Ehrenstein, M. R., Walport, M. J., et al. (2007). Increased positive selection of $\mathrm{B} 1$ cells and reduced $\mathrm{B}$ cell tolerance to intracellular antigens in clq-deficient mice. J. Immunol. 178, 2916-2922.

Fiskesund, R., Stegmayr, B., Hallmans, G., Vikström, M., Weinehall, L., de Faire, U., etal. (2010). Low levels of antibodies against phosphorylcholine predict development of stroke in a population-based study from Northern Sweden. Stroke 41, 607-612.
Flajnik, M., and Rumfelt, L. (2000). Early and natural antibodies in nonmammalian vertebrates. Curr. Top. Microbiol. Immunol. 252, 233-240.

Fraser, D. A., Laust, A. K., Nelson, E. L., and Tenner, A. J. (2009). Clq differentially modulates phagocytosis and cytokine responses during ingestion of apoptotic cells by human monocytes, macrophages, and dendritic cells. J. Immunol. 183, 6175-6185.

Friedman, P., Horkko, S., Steinberg, D. Witztum, J. L., and Dennis, E. A. (2002). Correlation of antiphospholipid antibody recognition with the structure of synthetic oxidized phospholipids. Importance of Schiff base formation and aldol condensation. J. Biol. Chem. 277, 7010-7020.

Griffin, D. O., Holodick, N. E., and Rothstein, T. L. (2011). Human B1 cells in umbilical cord and adult peripheral blood express the novel phenotype $\mathrm{CD} 20^{+} \mathrm{CD} 27^{+}$ $\mathrm{CD} 3^{+} \mathrm{CD}^{-}{ }^{-}$. J. Exp. Med. 208, 67-80.

Grillot-Courvalin, C., Brouet, J.-C., Labaume, S., Piller, F., Rassenti, L. Z., Silverman, G. J., et al. (1992). An antiB cell autoantibody from WiskottAldrich syndrome which recognizes i blood group specificity on normal human B cells. Eur. J. Immunol. 22, 1781-1788.

Grönwall, C., Akhter, E., Oh, C., Burlingame, R. W., Petri, M., and Silverman, G. J. (2012a). IgM autoantibodies to distinct apoptosisassociated antigens correlate with protection from cardiovascular events and renal disease in patients with SLE. Clin. Immunol. 142, 390-398.

Grönwall, C., Chen, Y., Vas, J., Khanna, S., Thiel, S., Corr, M., et al. (2012b). MAPK phosphatase1 is required for regulatory natural autoantibody-mediated inhibition of TLR responses. Proc. Natl. Acad. Sci. U.S.A. 109, 19745-19750.

Hammaker, D., and Firestein, G. S. (2010). "Go upstream, young man" lessons learned from the p38 saga. Ann. Rheum. Dis. 69, i77-i82.

Hardy, R. R. (2006). B-1 B cell development. J. Immunol. 177, 2749-2754.

Hardy, R. R., and Hayakawa, K. (2005). Development of $\mathrm{B}$ cells producing natural autoantibodies to thymocytes and senescent erythrocytes. Springer Semin. Immunopathol. 26, 363-375.

Hayakawa, K., Asano, M., Shinton, S. A., Gui, M., Allman, D., Stewart, C. L., et al. (1999). Positive selection of natural autoreactive B cells. Science 285, 113-116.

Jackson, K. J., Wang, Y., Gaeta, B. A., Pomat, W., Siba, P., Rimmer, J., et al. (2012). Divergent human populations show extensive shared IGK rearrangements in peripheral blood B cells. Immunogenetics 64, 3-14.

Jenne, C. N., Kennedy, L. J., and Reynolds, J. D. (2006). Antibody repertoire development in the sheep. Dev. Comp. Immunol. 30, 165-174.

Kantor, A. B., and Herzenberg, L. A. (1993). Origin of murine B lineages. Annu. Rev. Immunol. 11, 501-538.

Kearney, J. F. (2005). Innate-like B cells. Springer Semin. Immunopathol. 26, 377-383.

Kearney, J. F., Barletta, R., Quan, Z. S., and Quintáns, J. (1981). Monoclonal vs. heterogeneous anti-H8 antibodies in the analysis of the anti- phosphorylcholine response in BALB/c mice. Eur. J. Immunol. 11, 877-883.

Kleinau, S., Martinsson, P., and Heyman, B. (2000). Induction and suppression of collagen-induced arthritis is dependent on distinct fcgamma receptors. J. Exp. Med. 191, 16111616.

Kobie, J. J., Alcena, D. C., Zheng, B., Bryk, P., Mattiacio, J. L., Brewer, M., et al. (2012). 9G4 autoreactivity is increased in HIV-infected patients and correlates with HIV broadly neutralizing serum activity. PLoS ONE 7:e35356. doi: 10.1371/journal.pone.0035356

Korb, L. C., and Ahearn, J. M. (1997). $\mathrm{C} 1 \mathrm{q}$ binds directly and specifically to surface blebs of apoptotic human keratinocytes: complement deficiency and systemic lupus erythematosus revisited. J. Immunol. 158, 45254528.

Kulik, L., Fleming, S. D., Moratz, C., Reuter, J. W., Novikov, A., Chen, K., etal. (2009). Pathogenic natural antibodies recognizing annexin IV are required to develop intestinal ischemia-reperfusion injury. $J$. Immunol. 182, 5363-5373.

Leadbetter, E. A., Rifkin, I. R., Hohlbaum, A. M., Beaudette, B. C., Shlomchik, M. J., and MarshakRothstein, A. (2002). ChromatinIgG complexes activate $B$ cells by dual engagement of IgM and Toll-like receptors. Nature 416, 603-607.

Lemaitre, B., Nicolas, E., Michaut, L., Reichhart, J. M., and Hoffmann, J. A. (1996). The dorsoventral regulatory gene cassette spätzle/Toll/cactus controls the potent antifungal response in Drosophila adults. Cell 86, 973-983.

Liu, Y., Shepherd, E. G., and Nelin, L. D. (2007). MAPK phosphatases: regulating the immune response. Nat. Rev. Immunol. 7, 202-212. 
Lleo, A., Invernizzi, P., Gao, B., Podda, M., and Gershwin, M. E. (2010). Definition of human autoimmunity autoantibodies versus autoimmune disease. Autoimmun. Rev. 9, A259A266.

Lövgren, T., Eloranta, M.-L., Båve, U., Alm, G. V., and Rönnblom, L. (2004). Induction of interferon- $\alpha$ production in plasmacytoid dendritic cells by immune complexes containing nucleic acid released by necrotic or late apoptotic cells and lupus IgG. Arthritis Rheum. 50, 1861-1872.

Lutz, H. U. (ed.) (2012). Naturally Occurring Antibodies (NAbs). Austin, TX: Lands Bioscience.

Masmoudi, H., Mota-Santos, T., Huetz, F., Coutinho, A., and Cazenave, P. A. (1990). All T15 Id-positive antibodies (but not of VHT15 ${ }^{+}$antibodies) are produced by peritoneal $\mathrm{CD}^{+} \mathrm{B}$ lymphocytes. Int. Immunol. 2, 515-520.

Matsushita, M., Matsushita, A., Endo, Y., Nakata, M., Kojima, N., Mizuochi, T., et al. (2004). Origin of the classical complement pathway: lamprey orthologue of mammalian Clq acts as a lectin. Proc. Natl. Acad. Sci. U.S.A. 101, 10127-10131.

Mehrani, T., and Petri, M. (2011). IgM anti- $\$ 2$ glycoprotein I is protective against lupus nephritis and renal damage in systemic lupus erythematosus. J. Rheumatol. 38, 450-453.

Mercolino, T. J., Arnold, L. W., and Haughton, G. (1986). Phosphatidyl choline is recognized by a series of Ly$1^{+}$murine B cell lymphomas specific for erythrocyte membranes. J. Exp. Med. 163, 155-165.

Mi, Q. S., Zhou, L., Schulze, D. H., Fischer, R. T., Lustig, A., Rezanka, L. J., et al. (2000). Highly reduced protection against Streptococcus pneumoniae after deletion of a single heavy chain gene in mouse. Proc. Natl. Acad. Sci. U.S.A. 97, 6031-6036.

Moncho-Amor, V., Galardi-Castilla, M., Perona, R., and Sastre, L. (2011). The dual-specificity protein phosphatase MkpB, homologous to mammalian MKP phosphatases, is required for $D$. discoideum post-aggregative development and cisplatin response. Differentiation 81, 199-207.

Nandakumar, K. S., Svensson, L., and Holmdahl, R. (2003). Collagen type II-specific monoclonal antibody-induced arthritis in mice: description of the disease and the influence of age, sex, and genes. Am. J. Pathol. 163, 1827-1837.

Navratil, J. S., Watkins, S. C., Wisnieski, J. J., and Ahearn, J. M. (2001). The globular heads of C1q specifically recognize surface blebs of apoptotic vascular endothelial cells. J. Immunol. 166, 3231-3239.

Ogden, C. A., Decathelineau, A., Hoffmann, P. R., Bratton, D., Ghebrehiwet, B., Fadok, V. A., et al. (2001). C1q and mannose binding lectin engagement of cell surface calreticulin and CD91 initiates macropinocytosis and uptake of apoptotic cells. J. Exp. Med. 194, 781-795.

Paidassi, H., Tacnet-Delorme, P., Garlatti, V., Darnault, C., Ghebrehiwet, B., Gaboriaud, C., et al. (2008). Clq binds phosphatidylserine and likely acts as a multiligand-bridging molecule in apoptotic cell recognition. J. Immunol. 180, 2329-2338.

Pascual, V., and Capra, J. D. (1992). VH4-21, a human VH gene segment overrepresented in the autoimmune repertoire. Arthritis Rheum. 35 11-18.

Pascual, V., Victor, K., Lelsz, D., Spellerberg, M., Hamblin, T., Thompson, K., et al. (1991). Nucleotide sequence analysis of the $\mathrm{V}$ regions of two IgM cold agglutinins. Evidence that the VH4-21 gene segment is responsible for the major cross-reactive idiotype. J. Immunol. 146, 4385-4391.

Perlmutter, R., Kearney, J., Chang, S., and Hood, L. (1985). Developmentally controlled expression of immunoglobulin VH genes. Science 227, 1597-1601

Perrazio, S. F., Salomao, R., Silva, N. P., Carneiro-Sampaio, M., and Andrade, L. E. C. (2012). Serial screening shows that $28 \%$ of systemic lupus erythematosus adult patients carry an underlying primary immunodeficiency. Arthritis Rheum. 64, S284.

Pugh-Bernard, A. E., Silverman, G. J. Cappione, A. J., Villano, M. E., Ryan, D. H., Insel, R. A., et al. (2001). Regulation of inherently autoreactive VH4-34 B cells in the maintenance of human B cell tolerance. J. Clin. Invest. 108, 1061-1070.

Quartier, P., Potter, P. K., Ehrenstein, M. R., Walport, M. J., and Botto, M. (2005). Predominant role of IgM-dependent activation of the classical pathway in the clearance of dying cells by murine bone marrowderived macrophages in vitro. Eur. J. Immunol. 35, 252-260.

Rogosch, T., Kerzel, S., Hoß, K., Hoersch, G., Zemlin, C., Heckmann, M., etal. (2012). IgA response in preterm neonates shows little evidence of antigen-driven selection. $J$. Immunol. 189, 5449-5456.

Salojin, K. V., Owusu, I. B., Millerchip, K. A., Potter, M., Platt, K. A., and Oravecz, T. (2006). Essential role of MAPK phosphatase- 1 in the negative control of innate immune responses. J. Immunol. 176, 1899-1907.
Schroeder, H., Hillson, J., and Perlmutter, R. (1987). Early restriction of the human antibody repertoire. Science 238, 791-793.

Schroeder, H. W., and Wang, J. Y. (1990). Preferential utilization of conserved immunoglobulin heavy chain variable gene segments during human fetal life. Proc. Natl. Acad. Sci. U.S.A. 87, 6146-6150.

Seidl, K. J., MacKenzie, J. D., Wang, D., Kantor, A. B., Kabat, E. A., Herzenberg L. A., et al. (1997). Frequent occurrence of dentical heavy, and light chain Ig rearrangements. Int. Immunol. 9, 689-670.

Shaw, P. X., Hörkkö, S., Chang, M.-K., Curtiss, L. K., Palinski, W., Silverman, G. J., etal. (2000). Natural antibodies with the T15 idiotype may act in atherosclerosis, apoptotic clearance, and protective immunity. $J$. Clin. Invest. 105,1731-1740.

Shaw, P. X., Goodyear, C. S., Chang, M. K., Witztum, J. L., and Silverman, G. J. (2003). The autoreactivity of anti-phosphorylcholine antibodies for atherosclerosis-associated neo-antigens and apoptotic cells. J. Immunol. 170, 6151-6157.

Silberstein, L., Jefferies, L., Goldman, J., Friedman, D., Moore, J., Nowell, P., et al. (1991). Variable region gene analysis of pathologic human autoantibodies to the related $\mathrm{i}$ and I red blood cell antigens. Blood 78, 2372-2386.

Silverman, G. J., Chen, P., and Carson, D. (1990). Cold agglutinins: specificity, idiotypy and structural analysis. Chem. Immunol. 48, 109-125.

Sokolove, J., Zhao, X., Chandra, P. E., and Robinson, W. H. (2011). Immune complexes containing citrullinated fibrinogen costimulate macrophages via Toll-like receptor 4 and Fcg receptor. Arthritis Rheum. 63, 53-62.

Stuart, L. M., Takahashi, K., Shi, L., Savill, J., and Ezekowitz, R. A. (2005). Mannose-binding lectin-deficient mice display defective apoptotic cell clearance but no autoimmune phenotype. J. Immunol. 174, 3220-3226.

Su, J., Hua, X., Concha, H., Svenungsson, E., Cederholm, A., and Frostegård, J. (2008). Natural antibodies against phosphorylcholine as potential protective factors in SLE. Rheumatology 47, 1144-1150.

Sun, J., Hayward, C., Shinde, R., Christenson, R., Ford, S. P., and Butler, J. E. (1998). Antibody repertoire development in fetal and neonatal piglets. I. Four VH genes account for 80 percent of $\mathrm{VH}$ usage during 84 days of fetal life. J. Immunol. 161, 50705078 .
Terato, K., Hasty, K., Reife, R., Cremer, M., Kang, A., and Stuart, J. (1992). Induction of arthritis with monoclonal antibodies to collagen. $J$. Immunol. 148, 2103-2108.

Vas, J., Grönwall, C., Marshak-Rothsein, A., and Silverman, G. J. (2012). Natural antibody to apoptotic cell membranes inhibits the proinflammatory properties of lupus autoantibody immune complexes. Arthritis Rheum. 64, 3388-3398.

Wardemann, H., Yurasov, S., Schaefer, A., Young, J. W., Meffre, E., and Nussenzweig, M. C. (2003). Predominant autoantibody production by early human B cell precursors. Science 301, 1374-1377.

Yasuda, K., Richez, C., Maciaszek, J. W., Agrawal, N., Akira, S., Marshak-Rothstein, A., et al. (2007). Murine dendritic cell type I IFN production induced by human IgGRNA immune complexes is IFN regulatory factor (IRF) 5 and IRF7 dependent and is required for IL-6 production. J. Immunol. 178, 68766885.

Youd, M. E., Luus, L., and Corley, R. B. (2004). IgM monomers accelerate disease manifestations in autoimmune-prone Fasdeficient mice. J. Autoimmun. 23, 333-343.

Zhang, M., Alicot, E. M., and Carroll, M. C. (2008). Human natural IgM can induce ischemia/reperfusion injury in a murine intestinal model. Mol. Immunol. 245, 1036-1039.

Conflict of Interest Statement: The authors declare that the research was conducted in the absence of any commercial or financial relationships that could be construed as a potential conflict of interest.

Received: 12 August 2012; accepted: 03 January 2013; published online: 05 February 2013.

Citation: Vas J, Grönwall $C$ and Silverman GJ (2013) Fundamental roles of the innate-like repertoire of natural antibodies in immune homeostasis. Front. Immun. 4:4. doi: 10.3389/fimmu. 2013.00004

This article was submitted to Frontiers in B Cell Biology, a specialty of Frontiers in Immunology.

Copyright (c) 2013 Vas, Grönwall and Silverman. This is an open-access article distributed under the terms of the Creative Commons Attribution License, which permits use, distribution and reproduction in other forums, provided the original authors and source are credited and subject to any copyright notices concerning any third-party graphics etc. 